\title{
Sagittal plane lumbar intervertebral motion during seated flexion-extension radiographs of 658 asymptomatic nondegenerated levels
}

\author{
Blake N. Staub, MD, ${ }^{1}$ Paul J. Holman, MD, ${ }^{1}$ Charles A. Reitman, MD, ${ }^{2}$ and John Hipp, $\mathrm{PhD}^{3}$ \\ 'Department of Neurosurgery, Houston Methodist Neurological Institute, Methodist Hospital; 2Department of Orthopedic Surgery, \\ Baylor College of Medicine; and ${ }^{3}$ Medical Metrics Inc., Houston, Texas
}

\begin{abstract}
OBJECT Evaluation of lumbar stability is fundamentally dependent on a clear understanding of normal lumbar motion. There are inconsistencies in reported lumbar motion across previously published studies, and it is unclear which provide the most reliable reference data. New technology now allows valid and reliable determination of normal lumbar intervertebral motion (IVM). The object of this study was to provide normative reference data for lumbar IVM and center of rotation (COR) using validated computer-assisted measurement tools.

METHODS Sitting flexion-extension radiographs were obtained in 162 asymptomatic volunteers and then analyzed using a previously validated and widely used computerized image analysis method. Each lumbar level was subsequently classified as "degenerated" or "nondegenerated" using the Kellgren-Lawrence classification. Of the 803 levels analyzed, 658 were nondegenerated (Kellgren-Lawrence grade $<2$ ). At each level of the lumbar spine, the magnitude of intervertebral rotation and translation, the ratio of translation per degree of rotation (TPDR), and the position of the COR were calculated in the nondegenerative cohort. Translations were calculated in millimeters and percentage endplate width.
\end{abstract}

RESULTS All parameters were significantly dependent on the intervertebral level. The upper limit of the $95 \% \mathrm{Cls}$ for anteroposterior intervertebral translation in this asymptomatic cohort ranged from $2.1 \mathrm{~mm}(6.2 \%$ endplate width) to $4.6 \mathrm{~mm}$ (13.3\% endplate width). Intervertebral rotation upper limits ranged from $16.3^{\circ}$ to $23.5^{\circ}$. The upper limits for TPDR ranged from $0.49 \%$ to $0.82 \%$ endplate width/degree. The COR coordinates were clustered in level-dependent patterns.

CONCLUSIONS New normal values for IVM, COR, and the ratio of TPDR in asymptomatic nondegenerative lumbar levels are proposed, providing a reference for future interpretation of sagittal plane motion in the lumbar spine.

http://thejns.org/doi/abs/10.3171/2015.3.SPINE14898

KEY WORDS intervertebral motion; instantaneous axis of rotation; center of rotation; translation per degree of rotation; computer-assisted measurement; lumbar; flexion-extension

$\mathrm{B}$ ACK pain affects nearly $80 \%$ of people at one point in their lives and between $15 \%$ and $20 \%$ of people in any given year. ${ }^{22}$ Since one of the most important functions of the spine is providing a mobile "backbone" for controlled motion, documenting abnormal motion may help in the diagnosis of back pain.

Abnormal intervertebral motion (IVM) cannot be identified unless normal motion is well defined, and numerous studies have attempted to quantify normal lumbar IVM. ${ }^{17,9,10,13,17,21,24,28,32}$ In the context of IVM measurements from flexion-extension radiographs, stability can be defined as motion within the range found in radiographically normal and asymptomatic volunteers. Instability can be defined as motion outside of this normal range. Flexionextension radiography has been the most common modality for IVM and spinal stability assessments. Traditionally, both flexion and extension radiographs have been collected with patients or volunteers in a range of positions and have been analyzed by manually drawing and measuring lines on the images to assess for instability. The functional

ABBREVIATIONS COR = center of rotation; IVM = intervertebral motion; QMA = Quantitative Motion Analysis; TPDR = translation per degree of rotation.

SUBMITTED September 7, 2014. ACCEPTED March 25, 2015.

INCLUDE WHEN CITING Published online August 21, 2015; DOI: 10.3171/2015.3.SPINE14898. 
range of motion of the entire lumbar spine during typical activities of daily living has been reported to be between $3^{\circ}$ and $49^{\circ}$ in flexion and extension. ${ }^{\circ}$

For purposes of establishing a disability rating, the loss of motion segment integrity has been defined as translational IVM $>4.5 \mathrm{~mm}$ or rotational (flexion-extension) $\mathrm{IVM}>15^{\circ}$ at L1 $-2, \mathrm{~L} 2-3$, and L3-4; $>20^{\circ}$ at L4-5; or > $25^{\circ}$ at L5-S1. ${ }^{25}$ The level of evidence that supports these guidelines might be considered suboptimal. Numerous other studies have attempted to define normal range of motion in the lumbar spine. The heterogeneity in study designs as well as limited reproducibility and accuracy has led to a wide degree of variability in results and an uncertain definition of "normal" motion in the lumbar spine (Table 1). In addition to the measurement technique, patient effort and positioning in flexion and extension are also important. Miyasaka et al. have reported that the segmental, flexion-to-extension range of IVM varied from $0^{\circ}$ to $24^{\circ}$ and was significantly greater when maximal effort was given to flexing and extending the spine. ${ }^{24}$ Several investigators have recommended flexion and extension images from the seated position, but there are limited data available to aid in interpreting IVM from seated flexionextension studies. ${ }^{8,15}$

Computer-assisted methods are now available to significantly decrease measurement error and provide a much higher level of measurement accuracy. The accuracy of computerized systems has ranged from $0.4^{\circ}$ to $2.8^{\circ}$ for rotation and $0.5-1.5 \mathrm{~mm}$ for translations..$^{12,18,36}$ Zhao et al. noted that intervertebral sagittal rotation measurements (flexion and extension) by surgeons were significantly more variable and less accurate than those from computerized software. ${ }^{36}$

In addition to the quantity of IVM, the quality of motion may be important. The center of rotation (COR) is an often-cited measurement relating to overall spinal kinematics. According to Benzel, when a bending moment is applied to a rigid object in space, it causes rotation about an axis. ${ }^{5}$ In the spine this axis is referred to as the "center of rotation" and constitutes the position about which lumbar back muscles exert their moment during flexion, extension, and torsion. ${ }^{16}$ It can be calculated by finding the point of intersection of perpendicular bisectors of 2 points on a moving vertebral body. ${ }^{16}$

The COR can be used as an objective measure of dynamic spinal alignment, and past reports have shown that the centrode pattern of the COR, in fact, changes in the setting of instability. ${ }^{14}$ In addition to the COR, the amount of translation per degree of rotation (TPDR) has been proposed as a simple quality of motion metric. ${ }^{33}$

The purpose of this project was to update and improve the data on normal sagittal plane IVM, COR, and TPDR using previously validated computer-assisted methods as well as a flexion-extension method that provokes adequate motion at each level in the lumbar spine.

TABLE 1. Summary of studies reporting the average intervertebral rotation at each lumbar spine level over the last 60 years*

\begin{tabular}{|c|c|c|c|c|c|c|c|c|c|c|c|c|c|c|c|}
\hline \multicolumn{6}{|c|}{ Study Description } & \multicolumn{2}{|c|}{ L1-2 } & \multicolumn{2}{|c|}{ L2-3 } & \multicolumn{2}{|c|}{ L3-4 } & \multicolumn{2}{|c|}{ L4-5 } & \multicolumn{2}{|c|}{ L5-S1 } \\
\hline Authors & Year & $\begin{array}{c}\text { No. of } \\
\text { Persons }\end{array}$ & $\begin{array}{c}\text { Age } \\
\text { Range } \\
\text { (yrs) }\end{array}$ & $\begin{array}{l}\text { Imaging } \\
\text { Position }\end{array}$ & Pelvis & Avg & UL & Avg & UL & Avg & UL & Avg & UL & Avg & UL \\
\hline Tanz & 1953 & 39 & & Supine & Free & 5.6 & & 7.6 & & 8.6 & & 12.2 & & 8.2 & \\
\hline Allbrook & 1957 & 20 & & Stand & Free & 5.7 & 13.7 & 8.3 & 14.5 & 13.2 & 19.9 & 18.9 & 27.2 & 17.6 & 26.6 \\
\hline Clayson et al. & 1962 & 26 & & & & 12.6 & & 15.8 & & 15.9 & & 17.7 & & 18.7 & \\
\hline Froning \& Frohman & 1968 & 30 & $20-69$ & $\begin{array}{l}\text { Kneel/ } \\
\text { stand }\end{array}$ & Free & 17.0 & & 16.0 & & 13.0 & & 11.0 & & 9.0 & \\
\hline Hayes et al. & 1989 & 59 & & Sit/stand & Free & 7.0 & 14.0 & 9.0 & 16.0 & 10.0 & 18.0 & 13.0 & 20.0 & 14.0 & 27.0 \\
\hline Pearcey et al. & 1984 & 11 & $25-36$ & Stand & Fixed & 13.0 & 22.8 & 14.0 & 17.9 & 13.0 & 18.9 & 16.0 & 23.8 & 14.0 & 23.8 \\
\hline Boden \& Wiesel & 1990 & 40 & $19-43$ & Stand/sit & Free & 8.2 & 15.3 & 7.7 & 15.3 & 7.7 & 17.5 & 9.4 & 22.1 & 9.4 & 21.4 \\
\hline Dvorák et al. (force to pain) & 1991 & 41 & $18-50$ & Stand & Fixed & 11.9 & 16.3 & 14.5 & 19.0 & 15.3 & 19.3 & 18.2 & 24.1 & 17.0 & 25.5 \\
\hline Miyasaka et al. (max) & 2000 & 90 & $20-39$ & Stand & Free & 12.1 & 20.1 & 15.1 & 20.4 & 15.7 & 21.4 & 18.2 & 24.3 & 17.7 & 30.6 \\
\hline Miyasaka et al. (mod effort) & 2000 & 90 & $20-39$ & Stand & Free & 9.3 & 22.0 & 9.5 & 20.3 & 9.1 & 22.8 & 7.0 & 16.8 & 7.5 & 19.1 \\
\hline Lee et al. (max) & 2002 & 30 & $20-29$ & Stand & Free & 12.7 & 19.1 & 12.1 & 17.3 & 10.0 & 15.2 & 7.2 & 12.4 & 5.2 & 9.9 \\
\hline Wong et al. & 2004 & & & & & & & & & & & & & & \\
\hline Males & & 50 & $20-76$ & Stand & Free & 12.4 & 16.5 & 12.9 & 16.0 & 11.0 & 13.4 & 9.3 & 13.0 & 7.0 & 10.3 \\
\hline Females & & 50 & $20-76$ & Stand & Free & 14.4 & 19.1 & 11.0 & 14.3 & 14.4 & 17.5 & 10.7 & 13.8 & 7.6 & 10.5 \\
\hline Mellor et al. & 2014 & 40 & $21-50$ & $\begin{array}{l}\text { Passive, } \\
\text { supine }\end{array}$ & Fixed & & & 8.7 & 12.4 & 9.6 & 13.0 & 11.8 & 16.5 & & \\
\hline Current study & 2014 & 161 & $18-82$ & Seated & Free & 11.0 & 16.3 & 12.4 & 17.4 & 13.0 & 18.2 & 14.5 & 21.6 & 12.8 & 23.4 \\
\hline
\end{tabular}

Avg = average; $U L=$ upper limit.

* Not all publications reported an upper limit for rotation. If the publication provided the standard deviation, the UL was calculated as the mean value $\pm 1.96 \times$ standard deviation. Several of the studies reported motion either in increments of global motion or separately as the amount of flexion and the amount of extension. In those cases, the reported data were used to estimate rotation from the maximally flexed to maximally extended position. The standard deviation used to calculate the UL in those cases was the largest reported for the level. Values are expressed in degrees, unless indicated otherwise. 


\section{Methods}

\section{Demographics}

One hundred sixty-two subjects (78 males, 84 females) were recruited for this institutional review board-approved research study. Subjects were included if they were skeletally mature with no history of a spinal disorder, spinal surgery, or back pain or related symptoms that required a visit to a physician. The mean age of participants was 42.2 years (range 18-82 years). Seventy-six volunteers were younger than 40 years of age. Sixty-three participants were between 40 and 60 years old. Twenty-three subjects were older than 63 years.

\section{Flexion-Extension Radiographs}

All flexion-extension images were taken with the volunteer in the seated position on a stable, low-back, 4-legged chair (Fig. 1). The seated position was chosen based on recommendations in the literature, ${ }^{8,15}$ its use in multiple other studies, ${ }^{2,11,34}$ and clinical experience with low-back pain patients unable to flex and extend the spine from a standing position because of pain or apprehension. A specialized cushion (Infab Corp.) was placed behind the volunteer. This cushion was used since preliminary studies without it revealed that when persons sit with their back pressed into the $90^{\circ}$ angle between the seat and chair back, there is little or even paradoxical motion between L-1 and S-1. With the cushion, participants were prevented from sitting so far back in the chair, limiting the presence of paradoxical motion. The subjects were coached on how to maximally flex and extend their back prior to imaging. Maximal flexion radiographs were obtained with the volunteer flexed forward and grabbing the front legs of the chair as close to the ground as possible. The maximum extension radiographs were taken with the volunteer extended backward over the cushion. No neutral radiographs were obtained to minimize radiation exposure. The repeatability of the flexion-extension positioning was not tested to minimize radiation exposure.

To facilitate the accurate measurement of the vertebral body dimensions and translations, we embedded a steel ring with an inner diameter of $25.5 \mathrm{~mm}$ and an outer diameter of $34.7 \mathrm{~mm}$ into the cushion placed behind the volunteer. The ring was positioned so it would be in the midsagittal plane of the volunteer and close to the volunteer's back. A ring was used because its central diameter could always be discerned, regardless of the orientation of the radiograph or the degree of exposure. The known dimensions of the ring were then used to determine the scale factor of each radiograph.

\section{Image Analysis}

The radiographic images were subsequently uploaded to the Quantitative Motion Analysis (QMA) software (Medical Metrics Inc.), a computer-assisted tracking software that matches radiographic patterns of specific vertebrae between flexion and extension. The software utilizes variations in vertebrae size, shape, and density to appropriately register the flexion and extension images. The software allows identification of a specific vertebral pattern in 1 radiograph and searches for the same pattern

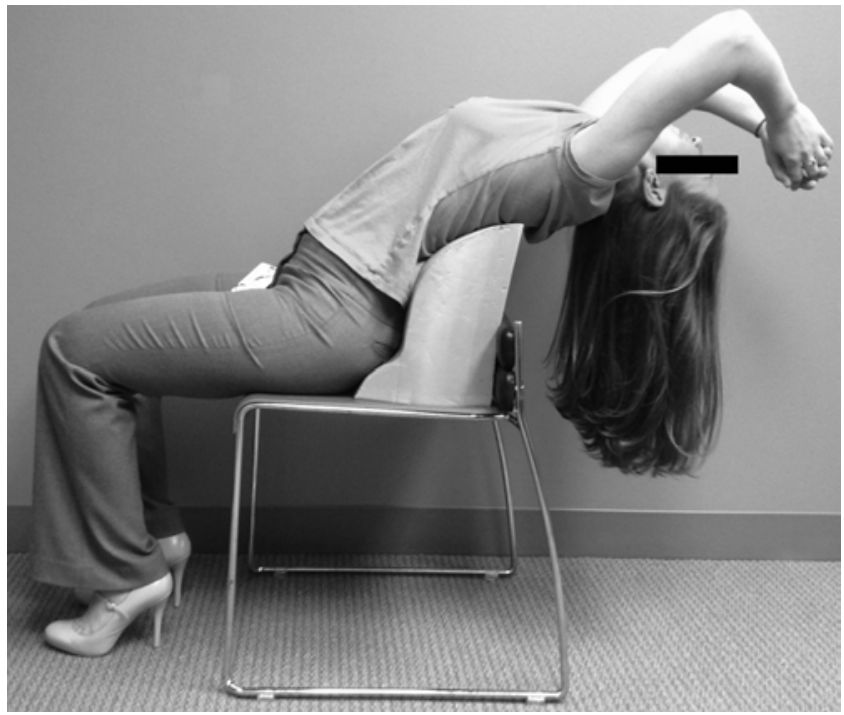

FIG. 1. All flexion-extension radiographs were taken with the volunteer in the seated position on a stable, low-back, 4-legged chair with a specialized cushion placed behind the volunteer.

on the other radiograph..$^{18}$ Once all vertebral bodies are spatially registered between the 2 images, it is possible to examine the IVM at each specific level using mathematical transformation matrices. The accuracy has been documented to be $0.47^{\circ} \pm 0.24^{\circ}$ in rotation and $0.54 \pm 0.34 \mathrm{~mm}$ in translation. ${ }^{36}$ Each set of radiographs was individually tracked and analyzed by trained analysts. The process was overseen by an imaging and software expert with more than 20 years of experience.

Three primary variables were measured from the flexion-extension images: translation motion-the displacement of the posterior inferior corner of the superior vertebra in the direction defined by the superior endplate of the inferior vertebra (Fig. 2); sagittal rotation-the angular change that occurs with flexion and extension; and location of the COR. Translation and rotation were measured as depicted in Fig. 3. The coordinates of the COR were only calculated when intervertebral rotation was $3^{\circ}$ or greater since preliminary reliability studies indicated that the COR cannot be reliably calculated when there is minimal rotation. In addition, it may not be logical to expect the COR to be in a reliable position when the spine is in the neutral zone..$^{30} \mathrm{~A}$ rotation less than $3^{\circ}$ is well below the normal flexion-extension neutral zone in the lumbar spine. ${ }^{26}$ The TPDR was calculated from the rotation and translation measurements (Fig. 2). The TPDR would also not be expected to be reliable until the restraints to IVM were exerting control of the motion, and it was only calculated when rotation was greater than $3^{\circ}$.

In addition, each vertebral level was graded for degeneration using the Kellgren-Lawrence scale. ${ }^{20}$ A single physician graded each level from 1 to 4 based on the degree of anterior/posterior osteophytes, endplate sclerosis, and disc space narrowing. Scores of 0 and 1 , signifying "no" or "doubtful" degeneration, were grouped together. Levels scored as 2 or above in any category were judged likely to be degenerated and thus were excluded from the remainder of the analysis. 

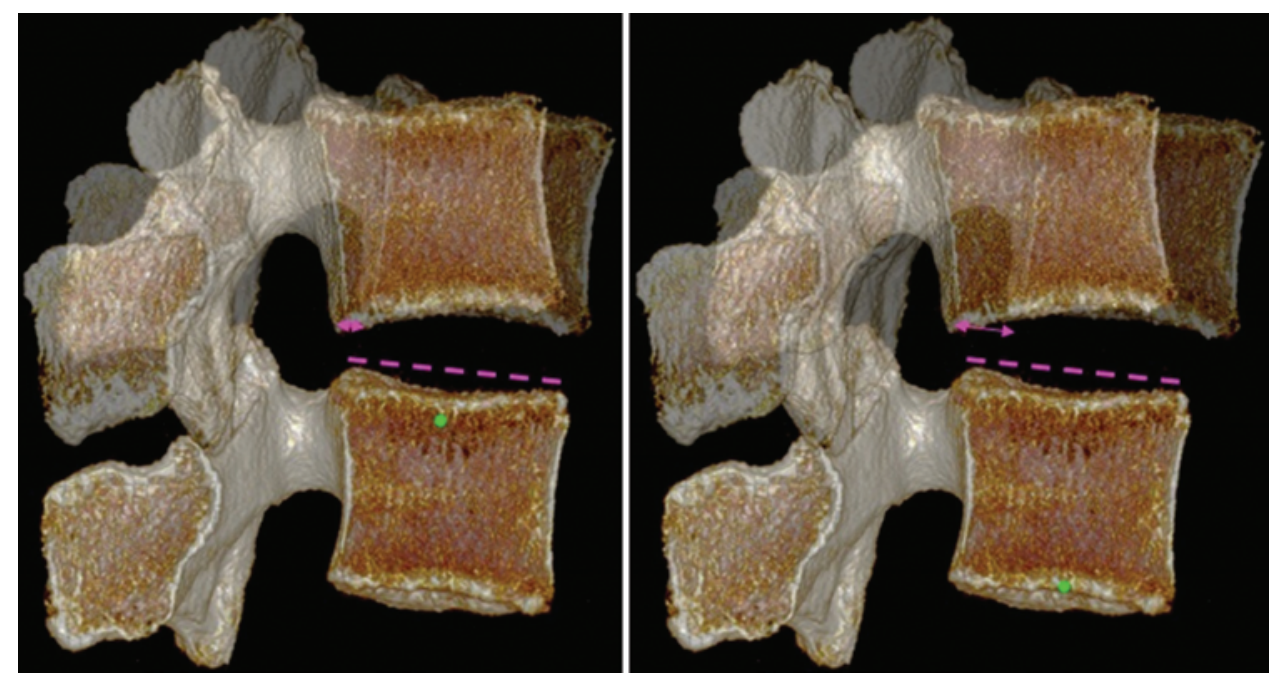

FIG. 2. Illustrations of a normal TPDR (left) and an abnormal TPDR (right) at the L4-5 level. In both, there is $13^{\circ}$ of intervertebral rotation between the flexed and extended positions. On the left, the rotation is about the green dot just below the superior endplate; and on the right, the rotation is about the green dot just above the inferior endplate. The translation (magenta arrows) is much greater with the abnormal TPDR. Translation is measured at the posterior inferior corner of the L-4 vertebral body in the direction defined by the superior endplate of the L-5 vertebral body (magenta dashed lines). Figure is available in color online only.

Data were analyzed by descriptive statistics and by using ANOVA to identify any significant differences between levels and other variables (Stata version 13, StataCorp LP). The descriptive statistics included the $95 \%$ upper and lower limits calculated as the mean $\pm 1.96 \times$ standard deviation. The most conservative approach to data analysis would be to exclude all data for the volunteer if any level in the spine was degenerated. For this reason, descriptive statistics were calculated both including all levels that were not degenerated and including levels only if there was no degenerated level in the spine. Readers can choose the approach and data most appropriate for their application. A p value $\leq$ 0.05 was considered significant.

\section{Results}

One set of radiographs from the 162 volunteers was extremely low quality and thus was excluded from the remaining analysis. Two additional L5-S1 levels could not be analyzed due to inadequate radiographic exposure. Of the 803 intervertebral levels analyzed using the QMA software, each was graded according to the Kellgren-Law-

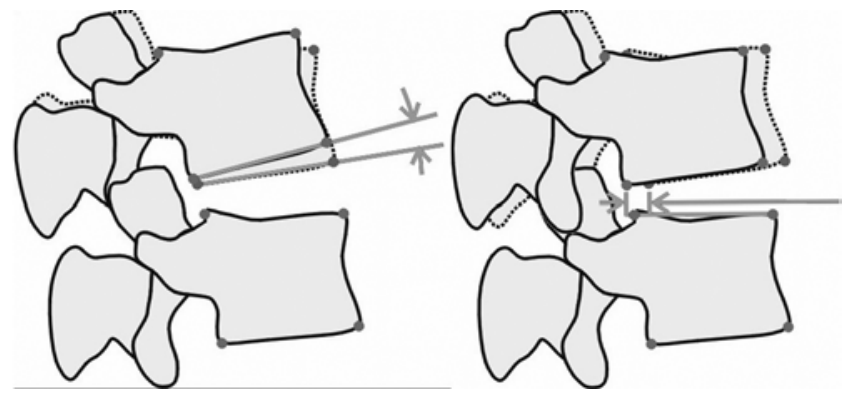

FIG. 3. Intervertebral rotation was measured as the rotation between flexion and extension of the superior vertebra relative to the inferior vertebra (left). Translation was measured as the displacement of the posterior inferior corner of the superior vertebra in a direction defined by the superior endplate of the inferior vertebra (right). rence scale as described above (Table 2). Some level of degeneration was seen at 145 of the 803 levels, with L5S1 being the most frequently affected. Excluding the degenerative levels, 658 nondegenerative lumbar levels were available for analysis. In 94 spines, there was no degenerated level. In 1 of those spines, the L5-S1 level could not be analyzed because of inadequate radiographic exposure.

\section{Intervertebral Rotation, Translation, and TPDR}

A multivariate ANOVA/ANCOVA test was done to analyze the effects of sex, age, global rotation, and intervertebral level on the amount of intervertebral rotation. Neither sex $(p=0.57)$ nor age $(p=0.24)$ was significant. Global rotation (L-1 to S-1) and intervertebral level were highly significant $(\mathrm{p}<0.0001)$. Based on a similar test with intervertebral translation as the dependent variable, sex was not significant $(\mathrm{p}=0.84)$, whereas age $(\mathrm{p}=0.0009)$, global rotation $(\mathrm{p}<0.0001)$, and level $(\mathrm{p}<0.0001)$ were. Further analysis by level revealed that only at L5-S1 was patient age significant, with the middle-age group (40-60 years) having greater translation on average than the younger (age $<40$ years) or older (age $>60$ years) groups. Since, with the one exception, the statistics supported pooling of the data (appreciating that variability in global rotation adds to variability in rotations and translations), it was decided to report only average values at each level and not separately report results for each sex and age group. According to multivariate ANOVA/ANCOVA to test the effects of sex, age, global rotation, and intervertebral level on TPDR,

TABLE 2. Degenerated lumbar spine levels in 161 asymptomatic volunteers

\begin{tabular}{lccccc}
\hline $\begin{array}{c}\text { Degeneration } \\
\text { Present }\end{array}$ & L1-2 & L2-3 & L3-4 & L4-5 & L5-S1 \\
\hline No & 131 & 135 & 139 & 143 & 110 \\
\hline Yes (\%) & $30(18.6)$ & $26(16.1)$ & $22(13.7)$ & $18(11.2)$ & $49(30.4)$ \\
\hline
\end{tabular}


TABLE 3. Rotation in nondegenerated spinal levels and spines*

\begin{tabular}{lccccc}
\hline \multicolumn{1}{c}{ Level } & $\begin{array}{c}\text { No. of } \\
\text { Volunteers }\end{array}$ & Mean & SD & LL & UL \\
\hline $\begin{array}{c}\text { Nondegenerated } \\
\text { spinal level }\end{array}$ & & & & & \\
\hline L1-2 & 131 & 11.02 & 2.70 & 5.72 & 16.33 \\
\hline L2-3 & 135 & 12.38 & 2.56 & 7.36 & 17.41 \\
\hline L3-4 & 139 & 13.02 & 2.63 & 7.87 & 18.18 \\
\hline L4-5 & 143 & 14.45 & 3.62 & 7.37 & 21.54 \\
\hline L5-S1 & 110 & 12.72 & 5.45 & 2.05 & 23.40 \\
\hline Nondegenerated spine & & & & & \\
\hline L1-2 & 94 & 11.03 & 2.68 & 5.78 & 16.28 \\
\hline L2-3 & 94 & 12.59 & 2.54 & 7.60 & 17.57 \\
\hline L3-4 & 94 & 13.29 & 2.66 & 8.07 & 18.51 \\
\hline L4-5 & 94 & 14.66 & 3.41 & 7.98 & 21.34 \\
\hline L5-S1 & 93 & 12.78 & 5.59 & 1.83 & 23.73 \\
\hline L 5 lowit; SD standard & & & & &
\end{tabular}

$\mathrm{LL}=$ lower limit; $\mathrm{SD}=$ standard deviation.

*Values expressed in degrees, unless indicated otherwise.

only intervertebral level was significant $(\mathrm{p}<0.0001)$. Sex $(p=0.42)$, age group $(p=0.09)$, and global rotation (L1$\mathrm{S} 1 ; \mathrm{p}=0.41$ ) were not significant. As expected, the TPDR ratio eliminated the dependence on global rotation.

In this group of volunteers, excluding the degenerated levels, the overall mean intervertebral rotation for all levels was $12.75^{\circ}: 11.02^{\circ}$ degrees at L1 $-2 ; 12.38^{\circ}$ at L2 $-3 ; 13.02^{\circ}$ at L3-4; $14.45^{\circ}$ at $\mathrm{L} 4-5$; and $12.72^{\circ}$ at L5-S1 (Table 3). The upper limit of normal for each level ranged from $16.3^{\circ}$ to $23.4^{\circ}$. The translation at each lumbar level is provided in Table 4. Overall, in this cohort of 658 asymptomatic lumbar levels, 8 levels $(1.22 \%)$ had greater than $4.5 \mathrm{~mm}$ of intervertebral translation, in all cases at the L3-4 or L4-5 level. The TPDR was calculated after first normalizing the translation to the anteroposterior endplate width. Overall, there was approximately $0.49 \%$ of TPDR at any given vertebral level. There was only $0.18 \%$ of translation at L5-S1 with each degree of rotation as compared with an average of $0.55 \%$ of translation at each of the other levels. The upper limit of the $95 \%$ CI was approximately 0.8 (\% endplate width/degree of rotation), although it varied significantly by level.

\section{Center of Rotation}

The COR was calculated using the QMA system for each intervertebral level in each of the 658 nondegenerative levels. The COR calculations were reported only if the intervertebral rotation was $>3^{\circ}$. The COR was reported as an anteroposterior (horizontal plane) and craniocaudal (vertical plane) coordinate. These coordinates were calculated with respect to an axis system affixed to the superior endplate of the inferior vertebra, with the origin at the middle of the endplate. The COR data for the nondegenerative levels appear in Tables 5 and 6 . Note that a positive value for the craniocaudal COR coordinate means that the COR was caudal to the superior endplate of the inferior vertebra. Figure 4 shows the COR for the $95 \%$ confidence intervals for the nondegenerated levels overlayed on a 3D reconstruction of a typical spine.

\section{Discussion}

The extent of IVM has been measured in many past studies, each with somewhat different techniques and varying degrees of accuracy and thus with varied results (Table 1). The present analysis of flexion-extension radiographs from 161 asymptomatic volunteers, encompassing 658 nondegenerated levels, is one of the largest in the literature.

To truly assess IVM, it is imperative that the subject's effort in flexing and extending their spine is maximized. Just as the true length and integrity of a rope cannot be determined unless it is stretched out and then measured under at least modest tension, the true amount of motion that can be achieved between vertebrae cannot be determined unless the supporting ligaments and disc are tensioned. The criteria for sufficient patient effort in flexionextension radiographs are not well defined in the scientific literature. Panjabi et al. have hypothesized that the aver-

TABLE 4. Translation in nondegenerated spinal levels and spines

\begin{tabular}{|c|c|c|c|c|c|c|c|c|c|}
\hline Level & $\begin{array}{c}\text { No. of } \\
\text { Volunteers }\end{array}$ & Mean $(\mathrm{mm})$ & $\mathrm{SD}(\mathrm{mm})$ & $\mathrm{LL}(\mathrm{mm})$ & UL (mm) & Mean (\%) & $\mathrm{SD}(\%)$ & LL (\%) & UL $(\%)$ \\
\hline \multicolumn{10}{|c|}{ Nondegenerated spinal level } \\
\hline L1-2 & 131 & 1.88 & 0.57 & 0.77 & 2.98 & 5.53 & 1.73 & 2.15 & 8.92 \\
\hline L2-3 & 135 & 2.42 & 0.69 & 1.07 & 3.77 & 6.93 & 2.04 & 2.92 & 10.94 \\
\hline L3-4 & 139 & 2.69 & 0.76 & 1.21 & 4.17 & 7.78 & 1.99 & 3.87 & 11.68 \\
\hline L4-5 & 143 & 2.66 & 0.99 & 0.72 & 4.6 & 7.77 & 2.81 & 2.27 & 13.28 \\
\hline L5-S1 & 110 & 0.53 & 0.87 & -1.18 & 2.23 & 1.57 & 2.60 & -3.52 & 6.66 \\
\hline \multicolumn{10}{|c|}{ Nondegenerated spine } \\
\hline L1-2 & 94 & 1.87 & 0.56 & 0.78 & 2.97 & 5.56 & 1.71 & 2.20 & 8.92 \\
\hline L2-3 & 94 & 2.44 & 0.70 & 1.08 & 3.80 & 7.08 & 2.12 & 2.93 & 11.23 \\
\hline L3-4 & 94 & 2.74 & 0.76 & 1.24 & 4.23 & 7.92 & 2.01 & 3.98 & 11.85 \\
\hline L4-5 & 94 & 2.75 & 0.86 & 1.06 & 4.45 & 8.16 & 2.60 & 3.07 & 13.25 \\
\hline L5-S1 & 93 & 0.52 & 0.92 & -1.28 & 2.32 & 1.59 & 2.77 & -3.85 & 7.02 \\
\hline
\end{tabular}

$\%=\%$ endplate width. 
TABLE 5. Anteroposterior coordinate of the COR in nondegenerated spinal levels and spines

\begin{tabular}{lccccc}
\hline \multicolumn{1}{c}{ Level } & $\begin{array}{c}\text { No. of } \\
\text { Volunteers }\end{array}$ & $\begin{array}{c}\text { Mean } \\
(\mathrm{mm})\end{array}$ & $\begin{array}{c}\text { SD } \\
(\mathrm{mm})\end{array}$ & $\begin{array}{c}\mathrm{LL} \\
(\mathrm{mm})\end{array}$ & $\begin{array}{c}\mathrm{UL} \\
(\mathrm{mm})\end{array}$ \\
\hline $\begin{array}{c}\text { Nondegenerated spinal } \\
\text { level }\end{array}$ & & & & & \\
\hline L1-2 & 131 & -6.58 & 6.99 & -20.28 & 7.13 \\
\hline L2-3 & 135 & -7.22 & 5.23 & -17.47 & 3.03 \\
\hline L3-4 & 139 & -7.34 & 4.80 & -16.75 & 2.07 \\
\hline L4-5 & 143 & -6.98 & 4.91 & -16.61 & 2.64 \\
\hline L5-S1 & 110 & -11.61 & 6.94 & -25.21 & 1.98 \\
\hline Nondegenerated spine & & & & & \\
\hline L1-2 & 94 & -6.28 & 6.24 & -18.51 & 5.94 \\
\hline L2-3 & 94 & -7.06 & 4.91 & -16.70 & 2.57 \\
\hline L3-4 & 94 & -7.49 & 4.88 & -17.06 & 2.08 \\
\hline L4-5 & 94 & -7.06 & 4.40 & -15.67 & 1.56 \\
\hline L5-S1 & 93 & -11.52 & 6.98 & -25.21 & 2.17 \\
\hline
\end{tabular}

age neutral zone for each level of the lumbar spine is $5^{\circ} .{ }^{27}$ To ensure that motion is outside the neutral zone, rotation would need to be at least $6^{\circ}$ at each level. Allowing for some measurement error, a practical patient-effort criterion might be at least $7^{\circ}$ of intervertebral rotation at 2 or more levels - at least for a limited assessment. Of the 161 volunteers in the current study, only 4 (2.5\%) did not meet the criterion of having at least $7^{\circ}$ of intervertebral rotation at 2 or more levels. This finding suggests that the seated technique can provoke sufficient IVM to allow documentation of the range of motion from a flexion-extension study of the lumbar spine. This simple criterion could be used even if some levels have been fused. However, it is important to appreciate that a sufficiently motivated patient may have access to more motion in their spine than is apparent from flexion-extension radiographs.

The amount of IVM measured at each level in the spine in the present study was within the range reported in multi-

TABLE 6. Craniocaudal coordinate of the COR in nondegenerated spinal levels and spines

\begin{tabular}{lcrrrc}
\hline \multicolumn{1}{c}{ Level } & $\begin{array}{c}\text { No. of } \\
\text { Volunteers }\end{array}$ & $\begin{array}{c}\text { Mean } \\
(\mathrm{mm})\end{array}$ & $\begin{array}{c}\text { SD } \\
(\mathrm{mm})\end{array}$ & $\begin{array}{c}\mathrm{LL} \\
(\mathrm{mm})\end{array}$ & $\begin{array}{c}\mathrm{UL} \\
(\mathrm{mm})\end{array}$ \\
\hline $\begin{array}{c}\text { Nondegenerated spinal } \\
\text { level }\end{array}$ & & & & & \\
\hline L1-2 & 131 & 8.36 & 7.21 & -5.78 & 22.50 \\
\hline L2-3 & 135 & 9.33 & 6.54 & -3.48 & 22.14 \\
\hline L3-4 & 139 & 11.07 & 6.55 & -1.77 & 23.92 \\
\hline L4-5 & 143 & 6.09 & 7.34 & -8.30 & 20.47 \\
\hline L5-S1 & 110 & -14.08 & 14.93 & -43.34 & 15.19 \\
\hline Nondegenerated spine & & & & & \\
\hline L1-2 & 94 & 8.33 & 6.71 & -4.83 & 21.48 \\
\hline L2-3 & 94 & 9.00 & 6.52 & -3.79 & 21.78 \\
\hline L3-4 & 94 & 10.25 & 6.45 & -2.39 & 22.90 \\
\hline L4-5 & 94 & 6.21 & 6.87 & -7.26 & 19.69 \\
\hline L5-S1 & 93 & -14.53 & 15.88 & -45.65 & 16.59 \\
\hline
\end{tabular}

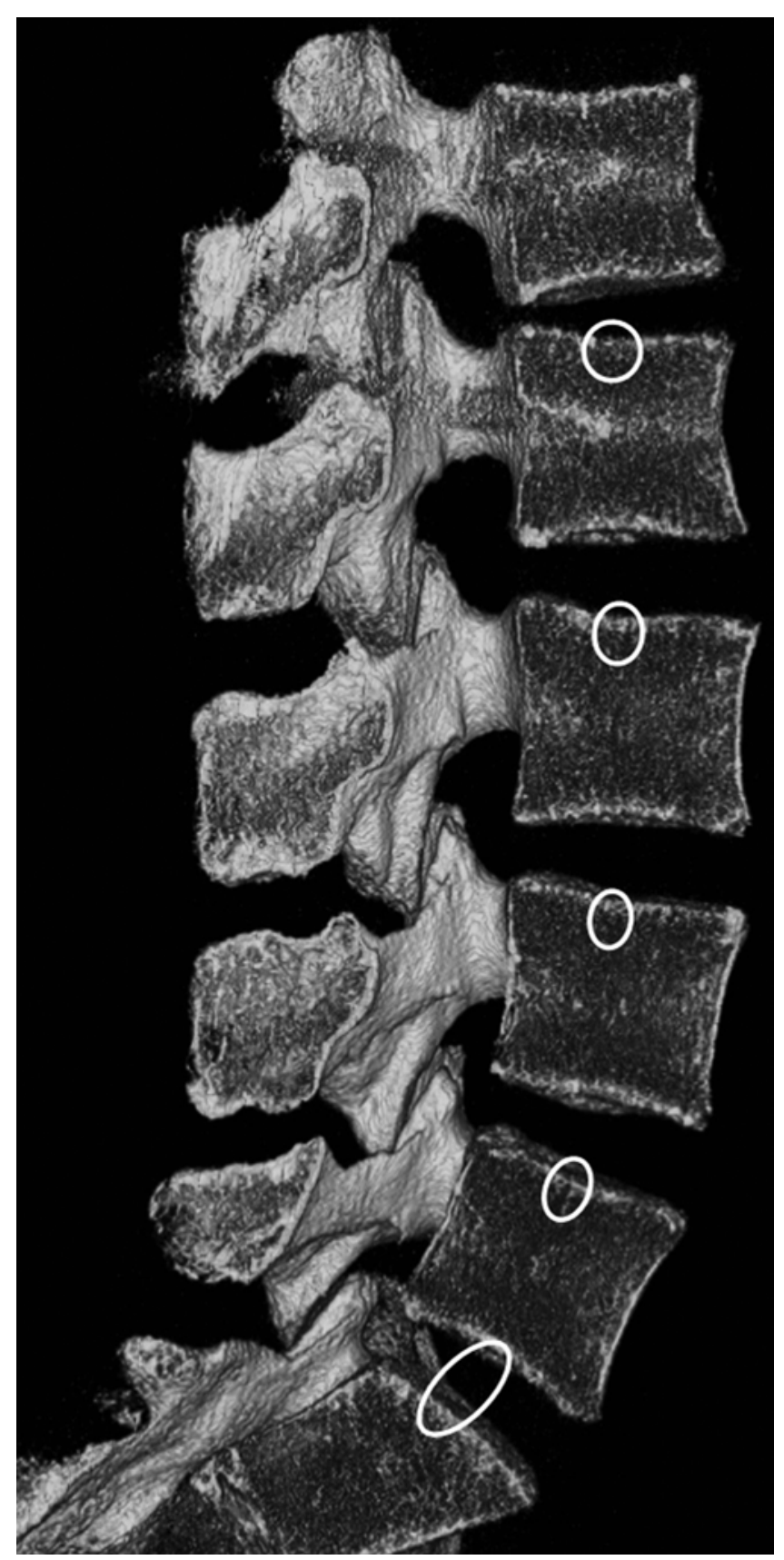

FIG. 4. Visual representation of the position of the COR in all nondegenerative levels. The ellipses show the $95 \%$ confidence intervals.

ple other studies (Table 1). This consistency with prior data suggests that the seated flexion-extension method used in our study did not create abnormal motion. Our intent in applying the seated technique was to use a method that could be easily reproduced in clinical practice and was easy for most patients to tolerate. Burkus and the members of a study group recommended flexion-extension studies with patients in the seated position since that position restricts pelvic and hip motion, enabling the technician to obtain consistent radiographic quality that demonstrates subtle changes. ${ }^{8}$ The seated technique, including the use of a cushion behind the patient's back, has also been used in upright MRI studies. ${ }^{2}$ Bending over and leaning back- 
ward from a seated position are also common activities of daily living, so the flexion-extension data have practical relevance.

Results in the current study indicated that the seated flexion-extension method can reliably generate enough motion at each level to ensure both that the motion is at least outside the neutral zone and that at least some of the restraints to IVM (for example, annulus, anterior and posterior longitudinal ligaments, and so forth) are being tensioned. We hypothesize that unless the flexion-extension test stresses the restraints to IVM, it is not reasonable to expect abnormalities in the restraints to be reliably detected. If the purpose of the flexion-extension test is to identify abnormal motion, it is important for the test to provoke abnormal motion if it can occur. It is known that at least in the cervical spine, even extensive damage to IVM restraints will not be detected unless there is at least a moderate amount of overall motion through the spine. ${ }^{19}$ The radiation exposure and the cost of flexion-extension radiographs may not be justifiable unless the test provokes abnormal motion if, in fact, abnormal motion can occur in the spine.

Many prior studies have suggested guidelines for defining normal intervertebral translation..$^{4,725}$ In this study the majority of subjects had less than $4.5 \mathrm{~mm}$ of translation at any level. Eight asymptomatic nondegenerated levels from the studied cohort translated more than $4.5 \mathrm{~mm}$. The lack of symptomatology implies clinical stability at these high translation levels. It appears that the degree of translation should not be used as a sole marker of instability. It is also of interest that translation at L5-S1 was markedly less than at the other lumbar levels.

Neither intervertebral rotation nor translation alone may be sufficient to provide evidence for or against spinal instability. However, the combination of intervertebral rotation and translation might provide a potential variable for assessing clinical instability. ${ }^{12,33}$ Findings outside of these reported normal levels could imply evidence of instability in a symptomatic patient. More studies are needed to look at this variable in populations with symptomatic and asymptomatic degenerative spines.

In the literature and in disability assessments, a frequently cited criterion of a specific IVM threshold has been used to identify an unstable spine. ${ }^{3,4}$ Our data suggest that existing instability criteria could lead to a substantial number of false-positive diagnoses. If one applies the guideline that motion is impaired when $>15^{\circ}$ at L1-2, L2-3, or L3-L4; > 20 $0^{\circ}$ at L4-5; or $>25^{\circ}$ at L5-S1, 3,4,25 then $10.61 \%$ of asymptomatic volunteers with radiographically normal discs would be classified as impaired at L1-2, $16.3 \%$ at $\mathrm{L} 2-3,22.30 \%$ at L3-4, 4.20\% at L4-5, and $0 \%$ at L5-S1. Our data agree with more recent data regarding the degree of IVM. ${ }^{24}$

The COR has been repeatedly discussed as a potential tool to evaluate spinal instability. In the present study the COR was based on the end range of motion, and the instantaneous axis of rotation that would exist at any point during the flexion-extension cycle might not be the same. In addition, the COR has been discussed in regards to its role in degeneration. Work by Rousseau et al. showed that forces exerted on the facet joints increased with variable positions of the COR. ${ }^{29}$ We know that after surgical procedures, as well as with idiopathic degeneration, the COR changes. ${ }^{16}$ In both cases, changes in the COR set up a perpetual cycle of further stress and degeneration. This study has provided new normal baselines for the COR in the nondegenerative spine. A follow-up study on the degenerative levels excluded from the present study is currently under way. Comparison of the asymptomatic degenerative and nondegenerative COR could demonstrate the clinical importance of this variable. Unfortunately, measuring the COR still requires sophisticated analysis, and thus its practical application remains limited at this time.

The ratio of TPDR has been previously proposed as a metric for spinal instability. ${ }^{33}$ The use of this metric can be rationalized by the hypothesis that the primary goal of motion in the spine is to facilitate positioning of the body through rotation between vertebrae. There is no logical reason why translation between vertebrae would be a primary goal of the body's motion control system. Rather, it is likely that the intervertebral translation observed in the normal spines is the minimum amount required to achieve the desired intervertebral rotation. With damage or degeneration of the motion constraints, the amount of translation for a given amount of rotation will increase. Past the neutral zone, translation increases with the magnitude of rotation. ${ }^{31}$ Both rotation and translation will depend on the effort exerted by the patient in flexing and extending the spine. However, the ratio between translation and rotation may be less dependent on patient effort, as observed in the motion data in the cohort studied.

This study is limited by its lack of complete volunteer medical histories. Although the inclusion criteria ruled out any volunteers with histories of back or radicular pain, there was no screening for previous trauma or other potential confounding histories. In addition, height and weight were not recorded for the volunteers, so it was not possible to determine if these variables or body mass index significantly affected IVM.

\section{Conclusions}

Given the findings of this study, new normal baseline values are suggested for intervertebral rotation, translation, TPDR, and position of the COR in radiographically and clinically normal lumbar spine levels. Comparison of these measures in this asymptomatic nondegenerative population with those in both asymptomatic and symptomatic degenerative cohorts would reveal the true clinical applicability of these variables.

\section{References}

1. Allbrook D: Movements of the lumbar spinal column. J Bone Joint Surg Br 39-B:339-345, 1957

2. Alyas F, Connell D, Saifuddin A: Upright positional MRI of the lumbar spine. Clin Radiol 63:1035-1048, 2008

3. Andersson B, Cocchiarella L, eds: Guides to the Evaluation of Permanent Impairment, ed 5. Chicago: American Medical Association, 2002

4. Balderston RA, Auerbach JD: The definition of lumbar spinal instability and its clinical significance. Semin Spine Surg 17:240-242, 2005

5. Benzel EC: Biomechanics of Spine Stabilization. Rolling 
Meadows, IL: American Association of Neurological Surgeons, 2001, p 526

6. Bible JE, Biswas D, Miller CP, Whang PG, Grauer JN: Normal functional range of motion of the lumbar spine during 15 activities of daily living. J Spinal Disord Tech 23:106-112, 2010

7. Boden SD, Wiesel SW: Lumbosacral segmental motion in normal individuals. Have we been measuring instability properly? Spine (Phila Pa 1976) 15:571-576, 1990

8. Burkus JK, Foley K, Haid RW, LeHuec JC: Surgical Interbody Research Group-radiographic assessment of interbody fusion devices: fusion criteria for anterior lumbar interbody surgery. Neurosurg Focus 10(4):E11, 2001

9. Clayson SJ, Newman IM, Debevec DF, Anger RW, Skowlund HV, Kottke F: Evaluation of mobility of hip and lumbar vertebrae of normal young women. Arch Phys Med Rehabil 43:1-8, 1962

10. Dvorák J, Panjabi MM, Chang DG, Theiler R, Grob D: Functional radiographic diagnosis of the lumbar spine. Flexion-extension and lateral bending. Spine (Phila Pa 1976) 16:562-571, 1991

11. Ferreiro Perez A, Garcia Isidro M, Ayerbe E, Castedo J, Jinkins JR: Evaluation of intervertebral disc herniation and hypermobile intersegmental instability in symptomatic adult patients undergoing recumbent and upright MRI of the cervical or lumbosacral spines. Eur J Radiol 62:444-448, 2007

12. Frobin W, Leivseth G, Biggemann M, Brinckmann P: Sagittal plane segmental motion of the cervical spine. A new precision measurement protocol and normal motion data of healthy adults. Clin Biomech (Bristol, Avon) 17:21-31, 2002

13. Froning EC, Frohman B: Motion of the lumbosacral spine after laminectomy and spine fusion. Correlation of motion with the result. J Bone Joint Surg Am 50:897-918, 1968

14. Gertzbein SD, Seligman J, Holtby R, Chan KH, Kapasouri A, Tile M, et al: Centrode patterns and segmental instability in degenerative disc disease. Spine (Phila Pa 1976) 10:257261, 1985

15. Goldstein C, Drew B: When is a spine fused? Injury 42:306-313, 2011

16. Haher TR, O’Brien M, Felmly WT, Welin D, Perrier G, Choueka J, et al: Instantaneous axis of rotation as a function of the three columns of the spine. Spine (Phila Pa 1976) 17 (6 Suppl):S149-S154, 1992

17. Hayes MA, Howard TC, Gruel CR, Kopta JA: Roentgenographic evaluation of lumbar spine flexion-extension in asymptomatic individuals. Spine (Phila Pa 1976) 14:327331, 1989

18. Hipp JA, Wharton ND: Quantitative motion analysis (QMA) of motion preserving and fusion technologies for the spine, in Yue JJ, Bertagnoli R, McAfee PC, et al (eds): Motion Preservation Surgery of the Spine: Advanced Techniques and Controversies. New York: Elsevier, 2008, pp 85-95

19. Hwang H, Hipp JA, Ben-Galim P, Reitman CA: Threshold cervical range-of-motion necessary to detect abnormal intervertebral motion in cervical spine radiographs. Spine (Phila Pa 1976) 33:E261-E267, 2008

20. Kellgren JH, Lawrence JS: Osteo-arthrosis and disk degeneration in an urban population. Ann Rheum Dis 17:388-397, 1958

21. Lee SW, Wong KW, Chan MK, Yeung HM, Chiu JL, Leong JC: Development and validation of a new technique for assessing lumbar spine motion. Spine (Phila Pa 1976) 27:E215-E220, 2002

22. Luo X, Pietrobon R, Sun SX, Liu GG, Hey L: Estimates and patterns of direct health care expenditures among individuals with back pain in the United States. Spine (Phila Pa 1976) 29:79-86, 2004
23. Mellor FE, Thomas PW, Thompson P, Breen AC: Proportional lumbar spine inter-vertebral motion patterns: a comparison of patients with chronic, non-specific low back pain and healthy controls. Eur Spine J 23:2059-2067, 2014

24. Miyasaka K, Ohmori K, Suzuki K, Inoue H: Radiographic analysis of lumbar motion in relation to lumbosacral stability. Investigation of moderate and maximum motion. Spine (Phila Pa 1976) 25:732-737, 2000

25. Panjabi MM: Clinical spinal instability and low back pain. J Electromyogr Kinesiol 13:371-379, 2003

26. Panjabi MM: The stabilizing system of the spine. Part II. Neutral zone and instability hypothesis. J Spinal Disord 5:390-397, 1992

27. Panjabi MM, Oxland TR, Yamamoto I, Crisco JJ: Mechanical behavior of the human lumbar and lumbosacral spine as shown by three-dimensional load-displacement curves. J Bone Joint Surg Am 76:413-424, 1994

28. Pearcy M, Portek I, Shepherd J: Three-dimensional x-ray analysis of normal movement in the lumbar spine. Spine (Phila Pa 1976) 9:294-297, 1984

29. Rousseau MA, Bradford DS, Hadi TM, Pedersen KL, Lotz JC: The instant axis of rotation influences facet forces at L5/ S1 during flexion/extension and lateral bending. Eur Spine J 15:299-307, 2006

30. Sengupta DK, Fan H: The basis of mechanical instability in degenerative disc disease: a cadaveric study of abnormal motion versus load distribution. Spine (Phila Pa 1976) 39:1032-1043, 2014

31. Stokes IA, Frymoyer JW: Segmental motion and instability. Spine (Phila Pa 1976) 12:688-691, 1987

32. Tanz SS: Motion of the lumbar spine; a roentgenologic study. Am J Roentgenol Radium Ther Nucl Med 69:399-412, 1953

33. Weiler PJ, King GJ, Gertzbein SD: Analysis of sagittal plane instability of the lumbar spine in vivo. Spine (Phila Pa 1976) 15:1300-1306, 1990

34. Weishaupt D, Schmid MR, Zanetti M, Boos N, Romanowski B, Kissling RO, et al: Positional MR imaging of the lumbar spine: does it demonstrate nerve root compromise not visible at conventional MR imaging? Radiology 215:247-253, 2000

35. Wong KW, Leong JC, Chan MK, Luk KD, Lu WW: The flexion-extension profile of lumbar spine in 100 healthy volunteers. Spine (Phila Pa 1976) 29:1636-1641, 2004

36. Zhao K, Yang C, Zhao C, An KN: Assessment of non-invasive intervertebral motion measurements in the lumbar spine. J Biomech 38:1943-1946, 2005

\section{Disclosure}

Dr. Hipp owns stock in Medical Metrics.

\section{Author Contributions}

Conception and design: Staub, Reitman, Hipp. Acquisition of data: Staub, Reitman, Hipp. Analysis and interpretation of data: Staub, Reitman, Hipp. Drafting the article: Staub, Holman, Hipp. Critically revising the article: all authors. Reviewed submitted version of manuscript: all authors. Approved the final version of the manuscript on behalf of all authors: Staub. Statistical analysis: Staub, Hipp. Administrative/technical/material support: Staub, Hipp. Study supervision: Hipp.

\section{Correspondence}

Blake N. Staub, Department of Neurosurgery, Houston Methodist Neurological Institute, 6560 Fannin St., Ste. 944, Houston, TX 77030. email: bnstaub@houstonmethodist.org. 